\title{
Fatty acids alter glycerolipid metabolism and induce lipid droplet formation, syncytialisation and cytokine production in human trophoblasts with minimal glucose effect or interaction
}

\author{
A.N. Pathmaperuma ${ }^{a}$, P. Maña ${ }^{a}$, S.N. Cheung ${ }^{a}$, K. Kugathas ${ }^{\text {a }}$, A. Josiah ${ }^{\text {a }}$, M.E. Koina ${ }^{\text {b }}$, A. Broomfield ${ }^{\text {, }}$, \\ V. Delghingaro-Augusto ${ }^{c}$, D.A. Ellwood ${ }^{\mathrm{d}}$, J.E. Dahlstrom ${ }^{\mathrm{b}, \mathrm{e}}$, C.J. Nolan ${ }^{\mathrm{a}, *}$ \\ ${ }^{a}$ Diabetes and Endocrinology Research Unit, Australian National University Medical School at The Canberra Hospital, Garran, ACT, Australia \\ ${ }^{\mathrm{b}}$ Anatomical Pathology, ACT PATHOLOGY, The Canberra Hospital, Garran, ACT, Australia \\ ${ }^{\mathrm{C}}$ Molecular Nutrition Unit and the Montreal Diabetes Research Center, University of Montreal and the CR-CHUM, Montreal, Ouebec, Canada \\ ${ }^{\mathrm{d}}$ Fetal Medicine Unit, Australian National University Medical School at The Canberra Hospital, Garran, ACT, Australia \\ e Anatomical Pathology, Australian National University Medical School at The Canberra Hospital, Garran, ACT, Australia
}

\section{A R T I C L E I N F O}

Article history:

Accepted 12 December 2009

\section{Keywords:}

Cytokine production

Diabetes

Fatty acid oxidation

Fatty acid esterification

Glucose metabolism

Lipid metabolism

Lipolysis

Lipid droplet

Non-esterified fatty acids

Placenta

Obesity

Syncytialisation

Trophoblast

\begin{abstract}
A B S T R A C T
The diabetic pregnancy is characterized by maternal hyperglycaemia and dyslipidaemia, such that placental trophoblast cells are exposed to both. The objective was to determine the effects of hyperglycaemia, elevated non-esterified fatty acids (NEFA) and their interactions on trophoblast cell metabolism and function.

Trophoblasts were isolated from normal term human placentas and established in culture for $16 \mathrm{~h}$ prior to experiments. Glucose utilisation, fatty acid oxidation and fatty acid esterification were determined using radiolabelled metabolic tracer methodology at various glucose and NEFA concentrations. Trophoblast lipid droplet formation including adipophilin mRNA expression, viability, apoptosis, syncytialisation, secretion of hormones and pro-inflammatory cytokines were also assessed.

Glucose utilisation via glycolysis was near maximal at the low physiological glucose concentration of $4 \mathrm{mM}$; whereas NEFA esterification into triacylglycerol and diacylglycerol increased linearly with increasing NEFA concentrations without evidence of plateau. Culture of trophoblasts in $0.25 \mathrm{mM}$ NEFA for $24 \mathrm{~h}$ upregulated fatty acid esterification processes, inhibited fatty acid oxidation, inhibited glycerol release (a marker of lipolysis) and promoted adipophilin and lipid droplet formation, all consistent with upregulation of fatty acid storage and buffering capacity. NEFA also promoted trophoblast syncytialisation and TNF $\alpha$, IL-1 $\beta$, IL- 6 and IL-10 production without effects on cell viability, apoptosis or hormone secretion. Hyperglycaemia caused intracellular glycogen accumulation and reduced lipid droplet formation, but had no other effects on trophoblast metabolism or function.

NEFA have effects on trophoblast metabolism and function, mostly independent of glucose, that may have protective as well as pathophysiological roles in pregnancies complicated by diabetes and/or obesity.
\end{abstract}

(C) 2009 Elsevier Ltd. All rights reserved.

\section{Introduction}

The rapid increasing prevalences of overweight, obesity, gestational diabetes and type 2 diabetes are adversely affecting women of childbearing age and their pregnancy outcomes. In a recent study, obese pregnant women had significantly increased rates of hypertensive disorders of pregnancy, prolonged hospital stays,

\footnotetext{
* Corresponding author at: Department of Endocrinology and Diabetes, The Canberra Hospital, PO Box 11, Woden, ACT 2606, Australia. Tel.: +61 26244 3794; fax: +6126244 4616

E-mail address: christopher.nolan@anu.edu.au (C.J. Nolan).
}

caesarean section, neonates with birth defects and neonates with hypoglycaemia [1]. From the hyperglycaemia and adverse pregnancy outcomes study, it is evident that even mild degrees of hyperglycaemia are associated with greater risk of large for gestational age (LGA) babies, clinical neonatal hypoglycaemia and raised cord blood C-peptide [2]. Of major concern are the very high rates of serious pregnancy complications, such as perinatal death and congenital malformations, occurring in pregnancies of women with type 2 diabetes [3-5]. While multiple factors are likely to be involved, the dyslipidaemia very often associated with these highrisk pregnancies may be important. 
Normal maternal metabolism in pregnancy is characterized by low normal glycaemia and physiological hyperlipidaemia [6-8]. Gestational diabetes, type 2 diabetes and poorly controlled type 1 diabetes, however, are often associated with even higher blood lipids than in normal pregnancy $[7,9,10]$. Obese women also have abnormal lipid profiles in pregnancy [11]. Women with higher range non-esterified fatty acids (NEFA) in the 3rd trimester are more likely to be overweight or obese [12]. Furthermore, elevated NEFA have been shown to be associated with pre-term delivery [12], intrauterine growth retardation (IUGR), IUGR with preeclampsia [13] and fetal adiposity [14].

Diabetes is well known to affect placental structure causing, in particular, abnormalities in terminal villous maturity and vascularisation [15-18]. Also placentas of women without diabetes but with LGA babies have an increase in placental abnormalities [16]. Functionally, there is good evidence that the human placenta adapts to even mild diabetes by limiting placental transfer of glucose, which may provide some degree of protection to the fetus [19-21]. This may be partly explained by a reduction in the expression of GLUT1 [20,22], which is the main glucose transporter in human placenta. Obesity and the placenta have been less well studied. Obesity is associated with larger placental size and placental macrophage accumulation and inflammation [23]. Knowledge about fatty acid metabolism in human placenta in pregnancies of diabetic and obese women is limited [24-27]. A recent study suggested that lipid metabolism genes in placenta are altered in different patterns in gestational diabetes and type 1 diabetes [28].

It was proposed by Prentki and Corkey that the toxicity of NEFA would be enhanced in the context of hyperglycaemia, a process termed glucolipotoxicity [29], as elevated glucose, via increasing malonyl-CoA, alters the partitioning of NEFA away from oxidation (a means of detoxification) towards acylation and esterification processes [30], some of which may be toxic if in excess. In support of this concept, we have previously reported a marked synergistic effect of high glucose and saturated NEFA in inducing cell death by apoptosis in both rat INS 832/13 pancreatic $\beta$-cells and human islets [31]. It is unknown if the process of glucolipotoxicity has a role in placenta in diabetic pregnancy.

The current study was performed in human trophoblasts from normal term placentas in primary culture in order to investigate the potential for glucolipotoxicity as a pathogenic process within the placenta. The effects of elevated glucose, elevated NEFA and, importantly, the combination of both on trophoblast metabolism, morphology, viability and function were investigated.

\section{Materials and methods}

2.1. Primary human trophoblast culture

The project was approved by the ACT Health Human Research Ethics Committee and informed consent was obtained from all women providing placentas. The placentas were from women undergoing elective caesarean sections at term $(>37$ weeks gestation). All were submitted for macroscopic and histological assessment (for details refer to the Electronic Supplemental Material (ESM)) to exclude unexpected pathology and none was found.

Trophoblasts were isolated according to a previously described method [32] with few modifications as described in the ESM. The harvested cells were cultured in CMRL medium 1066 containing $5.5 \mathrm{mM}$ glucose supplemented with 10\% FBS, $25 \mathrm{mM}$ HEPES, and antibiotic mix $(50 \mu \mathrm{g} / \mathrm{ml}$ penicillin, $50 \mu \mathrm{g} / \mathrm{ml}$ streptomycin and $100 \mu \mathrm{g} / \mathrm{ml}$ neomycin) (CMRL complete medium) and maintained at $37^{\circ} \mathrm{C}$ in a humidified atmosphere and $5 \% \mathrm{CO}_{2}$ for $16 \mathrm{~h}$ prior to experiments. At this stage, trophoblast purity was assessed by haematoxylin and eosin staining and immunocytochemical assessment as described in the ESM. All placental cultures showed greater than $95 \%$ purity for trophoblasts (ESM-Fig. 1)

Two series of experiments were performed. The first related to trophoblast glucose and fatty acid metabolism at this $16 \mathrm{~h}$ time-point. The second related to the effects of culturing the trophoblast for a further $24-48 \mathrm{~h}$ in RPMI 1640 medium with the same additives as for CMRL complete (RPMI complete), in low (1 mM) or high
(10 mM) glucose concentrations and $0.5 \%$ fatty acid free bovine serum albumin (BSA) (Sigma, castle Hill, NSW, Australia) in the presence or absence of $0.25 \mathrm{mM}$ NEFA (palmitate:oleate ratio, 1:1). Palmitate (C16:0) and oleate (C18:1) are the most prevalent NEFA in plasma and occur in a ratio of approximately 1:1 [33]. Various assessments of cell viability, metabolism and function were then performed.

\subsection{Preparation of BSA-bound fatty acids}

BSA-bound palmitate and oleate were prepared as described in the ESM.

\subsection{Glucose utilisation via glycolysis}

Trophoblasts $\left(1 \times 10^{6}\right.$ per well) were seeded in 6 well plates and cultures were established over $16 \mathrm{~h}$ as described above. Culture medium was removed and the cells were washed in Krebs Ringer Bicarbonate buffer with $10 \mathrm{mmol} / \mathrm{l} \mathrm{HEPES} \mathrm{(KRBH;} \mathrm{pH}$ 7.4 ) containing $0.5 \%$ defatted BSA (KRBH/0.5\%BSA) and $2 \mathrm{mM}$ glucose. The cells were then incubated in $0.75 \mathrm{ml}$ of $\mathrm{KRBH} / 0.5 \% \mathrm{BSA}$ containing $0.5,1.0,2.0,4.0,8.0$ and $16.0 \mathrm{mM}$ glucose and either $0.2 \mu \mathrm{Ci} / \mathrm{ml}\left[5-{ }^{3} \mathrm{H}\right]$ glucose $(10-20 \mathrm{Ci} / \mathrm{mmol}$, Perkin-Elmer Life Sciences, Waltham, MA) (for cold glucose concentrations $0.5-2.0 \mathrm{mM}$ ) or $0.4 \mu \mathrm{Ci}$ / $\mathrm{ml}\left[5-{ }^{3} \mathrm{H}\right]$ glucose (for cold glucose concentrations $4.0-16.0 \mathrm{mM}$ ) for $2 \mathrm{~h}$ at $37^{\circ} \mathrm{C}$ in a $5 \% \mathrm{CO}_{2}$ humidified incubator. The ${ }^{3} \mathrm{H}_{2} \mathrm{O}$ is released from $\left[5-{ }^{3} \mathrm{H}\right]$ glucose at the enolase step of glycolysis, such that it allows for the measurement of glycolytic flux from glucose. Calculations are derived from the rate of ${ }^{3} \mathrm{H}_{2} \mathrm{O}$ production (refer to ESM for measurement) and the specific activity of glucose in the media.

\subsection{Fatty acid oxidation and esterification}

Trophoblasts $\left(1 \times 10^{6}\right.$ per well) were seeded into 6 or 12 well plates at a density $1 \times 10^{6}$ cells/well and cultures were established over $16 \mathrm{~h}$, as described above. The 12 well plates were used for the second series of experiments. Culture medium was removed and the cells were washed in $\mathrm{KRBH} / 0.5 \% \mathrm{BSA}$ with $2 \mathrm{mM}$ glucose.

For fatty acid oxidation, trophoblasts were incubated in KRBH/0.5\%BSA containing $1 \mu \mathrm{Ci} / \mathrm{ml}\left[9,10(n)-{ }^{3} \mathrm{H}\right]$ palmitic acid $(30-60 \mathrm{Ci} / \mathrm{mmol}$, Perkin-Elmer Life Sciences), $0.1 \mathrm{mM}$ cold palmitate and $1.0 \mathrm{mM}$ L-carnitine (Sigma) at various glucose levels from 0.5 to $18.0 \mathrm{mM}$ for $2 \mathrm{~h}$ at $37{ }^{\circ} \mathrm{C}$ in a $5 \% \mathrm{CO}_{2}$ humidified incubator. Fatty acid oxidation was calculated from the amount of ${ }^{3} \mathrm{H}_{2} \mathrm{O}$ produced (refer to ESM for measurement) and the specific activity of fatty acid in the media.

For fatty acid esterification, trophoblasts were incubated in KRBH/0.5\%BSA containing $0.25 \mu \mathrm{Ci} / \mathrm{ml}$ of $\left[1^{-14} \mathrm{C}\right]$ palmitate $(40-60 \mathrm{Ci} / \mathrm{mmol}$, Perkin-Elmer Life Sciences) and 0.1-0.4 mM cold palmitate at various glucose concentrations for $2 \mathrm{~h}$ at $37^{\circ} \mathrm{C}$ in a $5 \% \mathrm{CO}_{2}$ humidified incubator. In a separate esterification experiment, trophoblasts were incubated in CRML complete with $0.5 \%$ BSA at 5.5 or $15 \mathrm{mM}$ glucose, $0.25 \mu \mathrm{Ci}\left[1^{-14} \mathrm{C}\right]$ palmitate and 0.2 or $0.4 \mathrm{mM}$ palmitate for $24 \mathrm{~h}$. At the end of the incubation period for all experiments the cells were washed and harvested in cold PBS, pelleted and resuspended in $3 \mathrm{ml}$ Folch reagent as previously described [34]. Total lipids were extracted and non-polar lipids were separated by thin-layer chromatography. Incorporation of labelled palmitate into phospholipids (PL), diacylglycerol (DAG) and triacylglycerol (TG) was quantified after scraping of bands from the plates and $\beta$-scintillation counting. Net esterification rates were calculated by correcting for the specific activity of fatty acid in the media.

\subsection{Glycerol release}

In order to assess lipolysis, glycerol release into the fatty acid esterification media (see above) over the course of the $2 \mathrm{~h}$ incubations was measured in indicated experiments. Glycerol concentrations in the media were determined by a coupled enzymatic reaction as previously described [35].

\subsection{Trophoblast viability, proliferation, apoptosis and protein content assays}

These methods are described in the ESM.

2.7. Assessment of cell aggregation, syncytia formation and oil red-O staining for lipid

These methods are described in the ESM.

\subsection{Electron microscopy}

Trophoblasts were cultured on sterilised collagen coated cover slips in the various conditions as indicated. Cell processing and examination by transmission electron microscopy (EM) is as described in the ESM.

\subsection{Adipophilin mRNA expression}

The method is described in the ESM. 

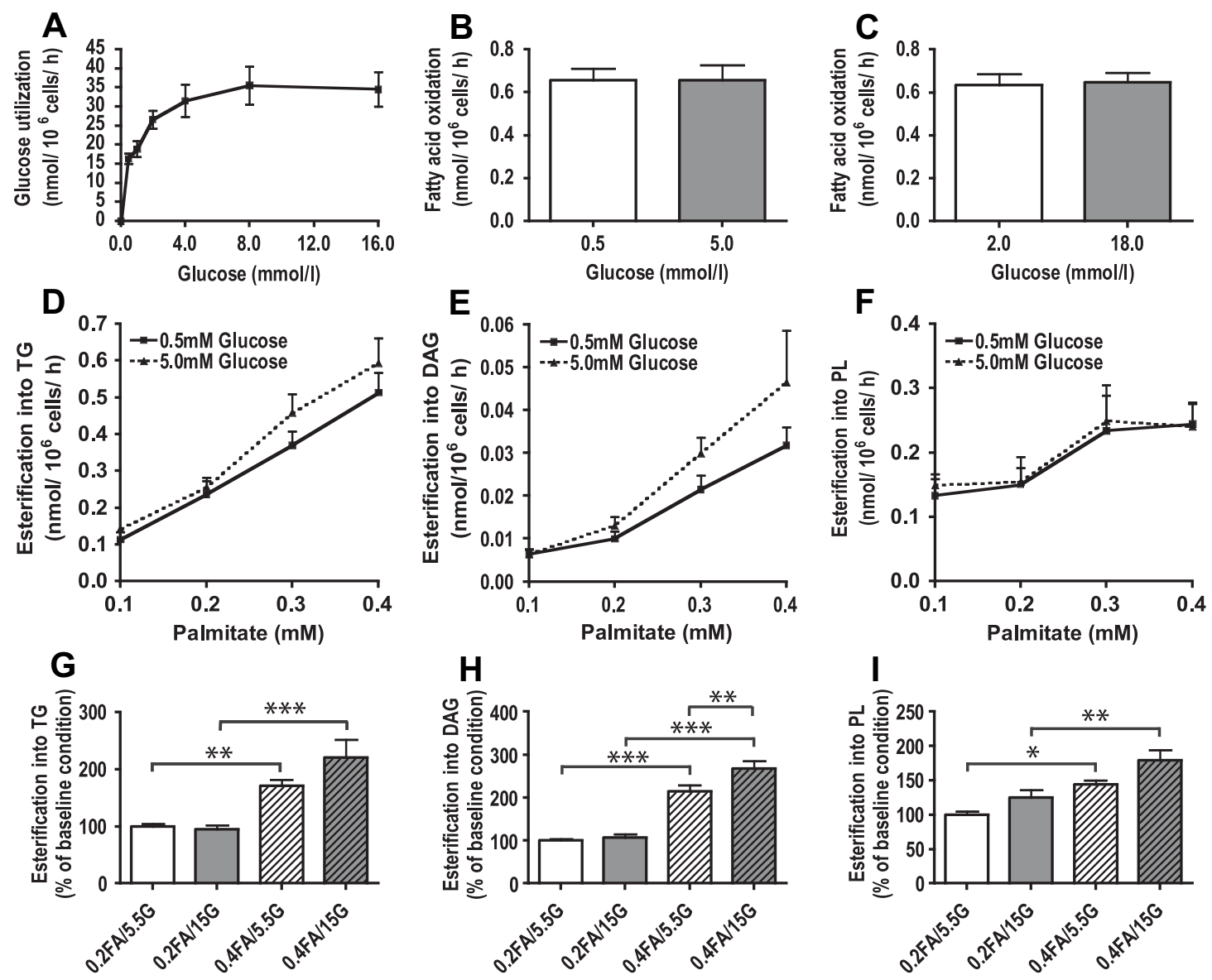

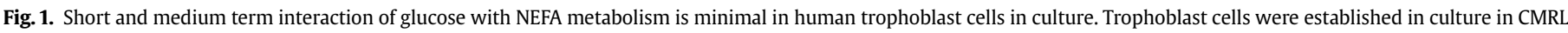

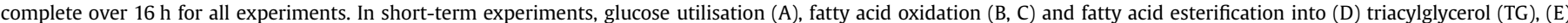

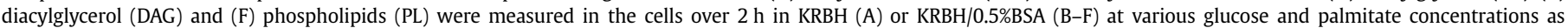

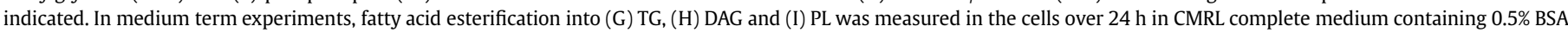

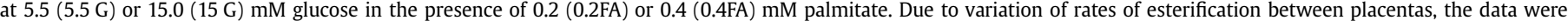

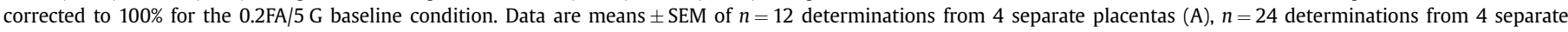

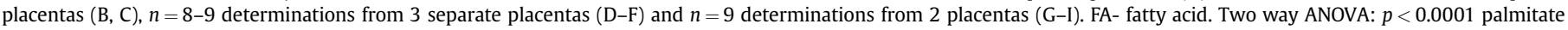
effect (D, E, G, H, I), $p<0.01$ palmitate effect (F), $p<0.05$ glucose effect (H), $p<0.01$ glucose effect (I). Bonferroni post hoc test: ${ }^{*} p<0.05$, ${ }^{* *} p<0.01$ and ${ }^{* * *} p<0.001$.

\subsection{Trophoblast hormone and cytokine secretion}

Trophoblast secretion of human chorionic gonadotrophin (beta-HCG), progesterone, human placental lactogen and the cytokines IL-1 $\beta$, IL-6, IL-8, IL-10 and TNF $\alpha$ were performed as described in the ESM.

\subsection{Statistical analysis}

Values are expressed as means \pm SEM. Statistical analysis was performed using two-way ANOVA or the Kruskal-Wallis test with, respectively, Bonferroni's or Dunn's post-test for multiple comparisons using GraphPad Prism v5.01 (GraphPad Software, San Diego, CA). For data not normally distributed, log transformations were performed prior to statistical analysis.

\section{Results}

3.1. Glucose ultilisation via glycolysis by trophoblasts in culture is near maximal at $4 \mathrm{mM}$ glucose

Glucose interacts with fatty acid partitioning via malonyl-CoA which is down-stream of glycolysis via the anaplerosis pathway [30]. In order to determine optimal glucose concentrations of the incubation media for the fatty acid partitioning experiments, we first determined the effects of the media glucose concentrations on glycolysis. The rate of glucose utilisation via glycolysis by trophoblasts was $90 \%$ of maximal at $4 \mathrm{mM}$ glucose and clearly maximum at $8 \mathrm{mM}$ glucose (Fig. $1 \mathrm{~A}$ ). From the Lineweaver-Burk plot of the data (not shown), the $V_{\max }$ for glucose utilisation was $35 \mathrm{nmol} / 10^{6}$ cells/h with a low $\mathrm{K}_{\mathrm{m}}$ of $0.6 \mathrm{mM}$ glucose.

\subsection{Glucose has no significant short-term effects on fatty acid oxidation or esterification processes in trophoblasts}

The short-term effect of glucose on fatty acid oxidation was assessed at glucose concentrations of 0.5 and $5.0 \mathrm{mM}$ (Fig. 1B) and 2.0 and $18.0 \mathrm{mM}$ (Fig. 1C), respectively. It was expected that a greater effect of glucose would be seen in the lower glucose range experiment because of the low $\mathrm{K}_{\mathrm{m}}$ of glucose for glucose utilisation in these cells (Fig. 1A). The glucose concentration of the incubation medium, however, had no effect on the rate of trophoblast fatty acid oxidation in either of the experiments (Fig. 1B and C). Fatty acid esterification into triglyceride (TG), diacylglycerol (DAG), and phospholipids (PL) was assessed at the glucose concentrations of 0.5 and $5.0 \mathrm{mM}$ at increasing concentrations of cold palmitate from 0.1 to $0.4 \mathrm{mM}$ (Fig. 1D-F). There was a trend for fatty acid esterification into TG and DAG to be increased at the $5.0 \mathrm{mM}$ compared to the $0.5 \mathrm{mM}$ glucose concentration (two-way ANOVA, $p=0.08$ for both) only at the higher NEFA concentrations (Fig. 1D and E). Glucose had 
no effect on fatty acid esterification into PL (Fig. 1F). Importantly, esterification into TG and DAG increased linearly with increasing concentrations of palmitate without evidence of plateau (Fig. 1D and E). Fatty acid esterification into PL, however, did appear to reach a maximum at the fatty acid concentration of $0.3 \mathrm{mM}$ (Fig. 1F).

\subsection{Glucose interacts with fatty acid esterification processes measured over $24 \mathrm{~h}$ in human trophoblasts, but only at the highest NEFA concentration}

As a plateau effect of NEFA concentration on NEFA esterification into DAG and TG was not evident at $2 \mathrm{~h}$, longer duration experiments were performed, as regulatory processes to prevent excess glycerolipid accumulation could develop gradually. Trophoblasts were cultured for $24 \mathrm{~h}$ at 5.5 or $15.0 \mathrm{mM}$ glucose in the presence of 0.2 or $0.4 \mathrm{mM}$ cold palmitate and $\left[1^{-14} \mathrm{C}\right]$ palmitate tracer. The glucose concentration of the culture medium enhanced $24 \mathrm{~h}$ fatty acid esterification processes into DAG and PL, with a trend for it to be increased into TG, this being most evident in cells exposed to the higher $0.4 \mathrm{mM}$ palmitate concentration (Fig. 1G-I). The increased esterification of palmitate into TG and DAG in cells exposed to $0.4 \mathrm{mM}$ compared to $0.2 \mathrm{mM}$ palmitate for $24 \mathrm{~h}$ was in proportion to, or exceeded, the 2 fold increased palmitate concentration (Fig. $1 \mathrm{G}$ and $\mathrm{H}$ ) such that there was no evidence for down-regulation of esterification into DAG and TG in response to longer term high NEFA exposure. Esterification into PL over $24 \mathrm{~h}$ was approximately $50-75 \%$ increased at the higher palmitate concentration suggesting some regulation into these complex glycerolipids (Fig. 1I).

\subsection{Effects of glucose and NEFA on trophoblast aggregation and oil red-O staining for lipid}

Subsequent experiments were performed on trophoblasts cultured for $24-48 \mathrm{~h}$ in RPMI complete medium containing $0.5 \%$ BSA at 1 or $10 \mathrm{mM}$ glucose in the presence or absence of $0.25 \mathrm{mM}$ NEFA (palmitate:oleate ratio 1:1). These concentrations were chosen after consideration of the glycolysis data (Fig. 1A). At $1 \mathrm{mM}$ and $10 \mathrm{mM}$ glucose, glycolysis was about half and fully maximal, respectively, such that down-stream flux into malonyl-CoA would likely differ between the 2 conditions. After 48 h, light microscopic examination of the cells in culture showed no obvious effect of the glucose concentration. Trophoblasts were predominantly found as single cells at 1 and $10 \mathrm{mM}$ glucose in the absence of NEFA (Fig. 2Aupper panels and 2C). The NEFA mix, however, markedly induced cell aggregation with the suggestion of syncytia formation (Fig. 2Aupper panels and 2C). This effect of the NEFA was not altered by the glucose concentration. NEFA induction of syncytialisation was confirmed by immunostaining cells for desmoplakin that delineates the cell membrane together with DAPI staining of nuclei (Fig. 2B and D). Oil red-O staining showed the presence of lipid droplets by $6 \mathrm{~h}$ (not shown) and marked lipid droplet accumulation by $24 \mathrm{~h}$ only in cells cultured in the presence of NEFA (Fig. 2A-lower panels) without obvious glucose effect. There was, however, evidence of non-lipid staining vacuolation in the trophoblast cells cultured in $10 \mathrm{mM}$ glucose suggestive of glycogen accumulation. Periodic acid Schiff (PAS) positive cells were seen, but this was variably removed with diastase, suggesting some non-specific staining. For this reason, quantitative assessment of glycogen by this method was not possible. The presence of glycogen at the higher glucose concentration was confirmed by EM (Fig. 3).

\subsection{Effects of glucose and NEFA on trophoblast ultrastructure}

Transmission EM was performed on trophoblasts cultured for $24 \mathrm{~h}$ at 1 or $10 \mathrm{mM}$ glucose in the presence or absence of
$0.25 \mathrm{mM}$ NEFA (palmitate:oleate ratio 1:1). Glycogen lakes were abundant only in cells cultured at $10 \mathrm{mM}$ glucose and lipid droplets and myelin figures were abundant only in cells incubated in the presence of NEFA (Fig. 3A-D). On blinded analysis, lipid droplets in the presence of NEFA were reported to be less abundant in cells cultured at $10 \mathrm{mM}$ compared to $1 \mathrm{mM}$ glucose (ESM-Table 1).

3.6. Trophoblast viability, apoptosis, protein content, beta-HCG, placental lactogen and progesterone secretion are not affected by NEFA or glucose

Trophoblasts were cultured in RPMI complete medium containing $0.5 \% \mathrm{BSA}$ at 1 or $10 \mathrm{mM}$ glucose in the presence or absence of $0.25 \mathrm{mM}$ NEFA (palmitate:oleate ratio, 1:1) for 24-48 h. Cell viability as assessed by MTT assay, apoptosis as assessed by caspase-3/7 activity assay and protein content were not altered by any of the culture conditions (ESM-Fig. 2). Trophoblast beta-HCG, placental lactogen and progesterone secretion over $48 \mathrm{~h}$ were also not affected (ESM-Fig. 2).

\subsection{Fatty acid metabolic partitioning in trophoblast cells is altered} by culture in the presence of NEFA without interaction with glucose

In order to investigate whether longer term exposure of the trophoblasts to elevated glucose and/or NEFA altered fatty acid metabolism, trophoblasts were cultured for $24 \mathrm{~h}$ in RPMI complete medium containing $0.5 \% \mathrm{BSA}$ at 1 or $10 \mathrm{mM}$ glucose in the presence or absence of $0.25 \mathrm{mM}$ NEFA (palmitate:oleate ratio, 1:1). Fatty acid partitioning into esterification and oxidation pathways, in addition to glycerol release, were then measured over $2 \mathrm{~h}$ in $\mathrm{KRBH} / 0.5 \% \mathrm{BSA}$ medium at 1.0, 5.0 and $15.0 \mathrm{mM}$ glucose. Consistent with the shortterm experiments at NEFA concentrations less than $0.3 \mathrm{mM}$, the glucose concentration in the $\mathrm{KRBH} / 0.5 \% \mathrm{BSA}$ incubation medium (1.0, 5.0 or $15.0 \mathrm{mM}$ glucose) had no effect on any of the fatty acid partitioning parameters measured (Fig. 4A-E). Furthermore, culture of trophoblasts for $24 \mathrm{~h}$ in low $(1 \mathrm{mM})$ or high $(10 \mathrm{mM})$ glucose had no effect (Fig. 4A-E). The presence of NEFA in the culture medium for $24 \mathrm{~h}$, however, altered all measured components of fatty acid partitioning. Treatment of the cells in culture with the $0.25 \mathrm{mM}$ NEFA mix resulted a $50-100 \%$ increase in fatty acid esterification into TG (Fig. 4A), a 10-20\% increase in fatty acid esterification into DAG (Fig. 4B), 20-50\% reduction in fatty acid esterification into PL (Fig. 4C) and a 10-20\% reduction in fatty acid oxidation (Fig. 4D). Glycerol release, generated by lipolysis of glycerolipids, was reduced up to $60 \%$ by treatment in culture with NEFA (Fig. 4E). The effects of NEFA on lipid partitioning were not altered by the glucose concentration of the medium.

\subsection{Culture of trophoblast cells in the presence of NEFA upregulates} the expression of adipophilin mRNA which is attenuated by higher glucose concentrations

In order to further assess the accumulation of lipid droplets in the presence of NEFA, the expression of the lipid droplet-associated protein adipophilin at the mRNA level was assessed. Within $6 \mathrm{~h}$, NEFA in the presence of $1 \mathrm{mM}$ glucose dramatically increased adipophilin expression (Fig. 4F). This effect, however, was markedly attenuated by a glucose concentration of $10 \mathrm{mM}$ (Fig. 4F). This result is consistent with the rapid appearance of lipid droplets in the NEFA treated cells observed with red oil O staining. The glucose effect on NEFA-induced adipophilin is also consistent with the EM finding of less lipid droplets at the higher glucose concentration (ESM-Table 1). 
A

No FA
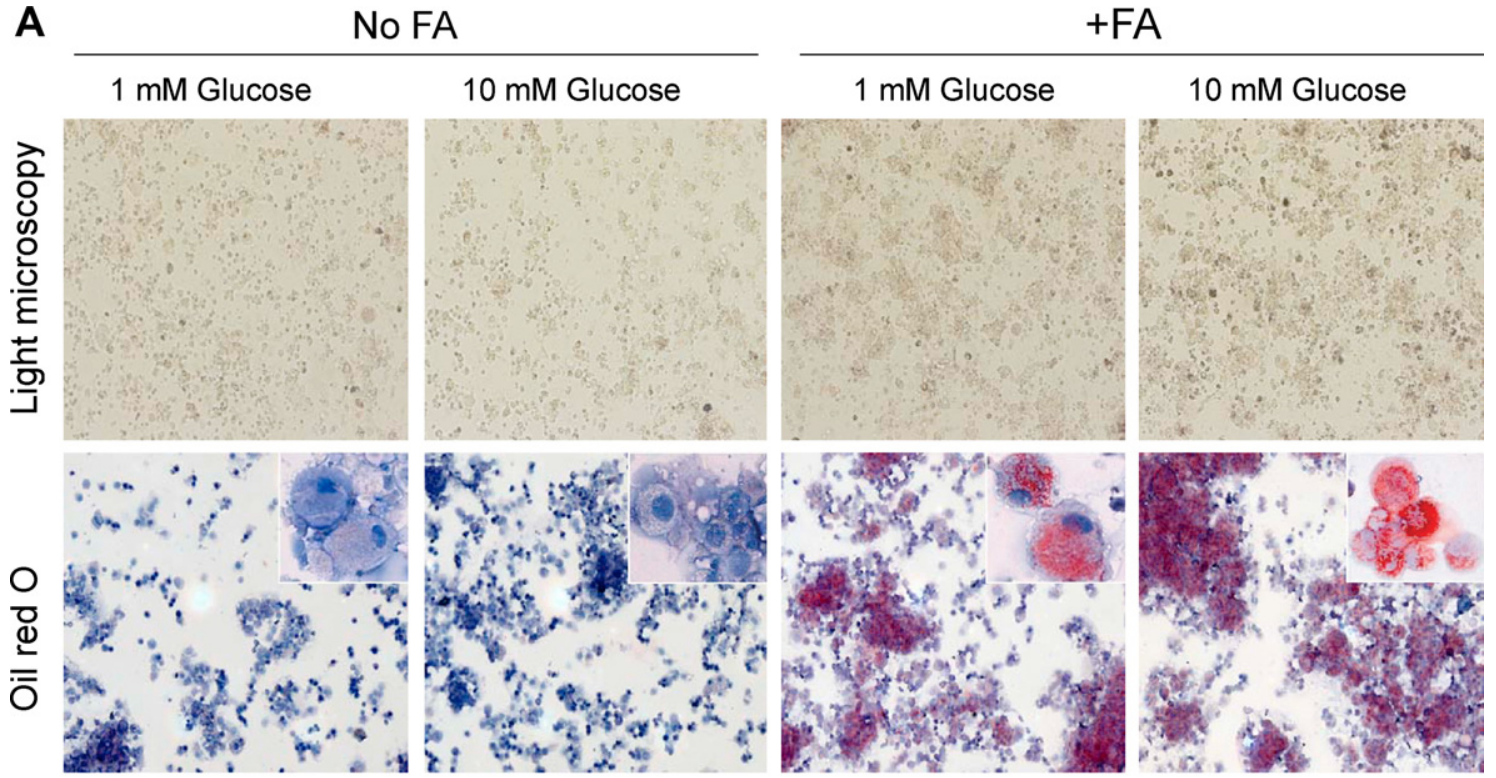

B

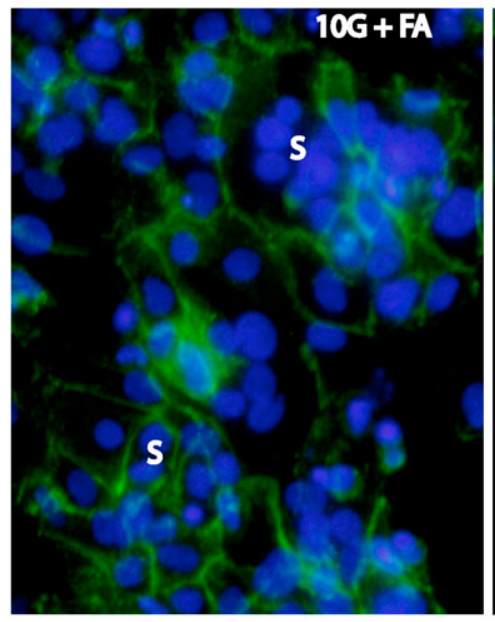

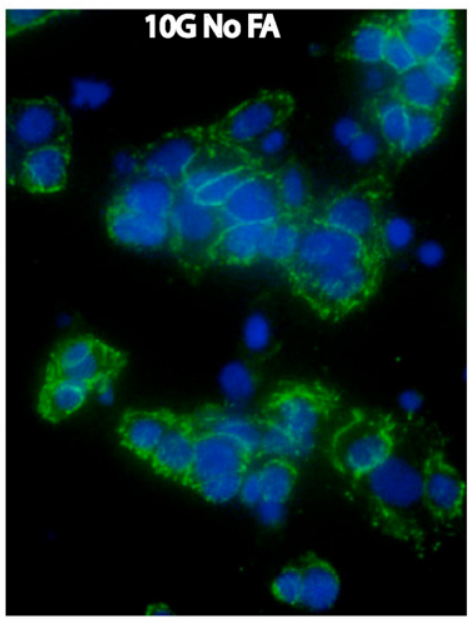

C

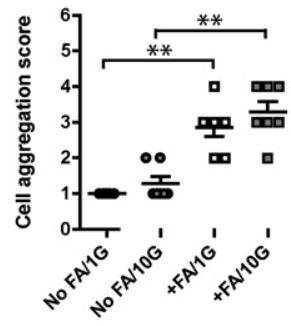

D

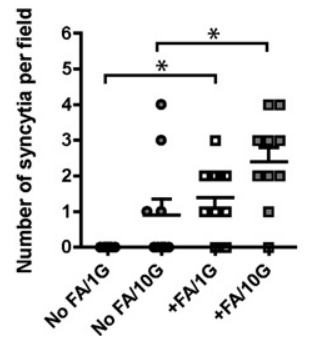

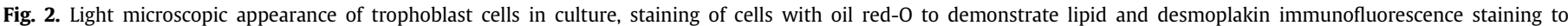

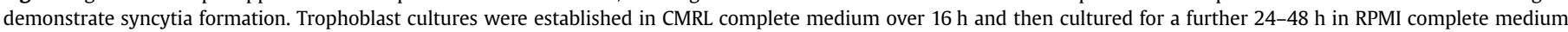

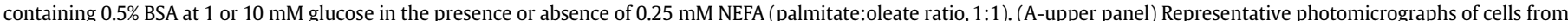

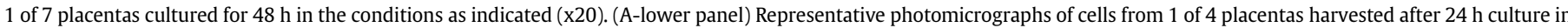

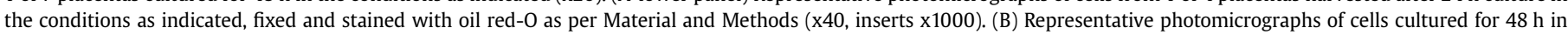

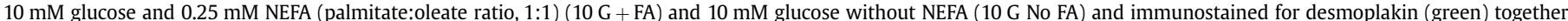

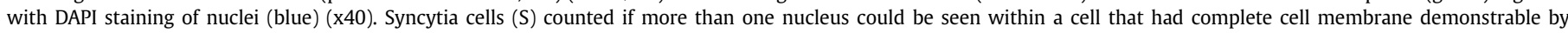

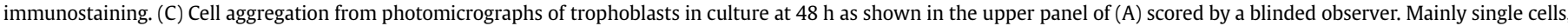

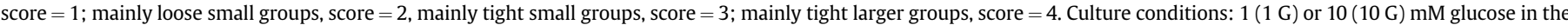

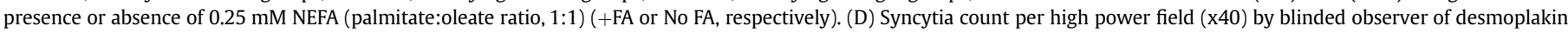

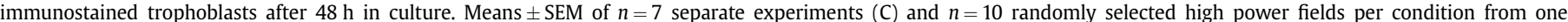
experiment (D). Kruskal-Wallis test: $p<0.0001$ (C), $p<0.001$ (D). Dunn's multiple comparison post hoc test: ${ }^{*} p<0.05,{ }^{* *} p<0.01$.

\subsection{NEFA increase pro-inflammatory cytokine production in human trophoblasts}

In order to determine if exposure of trophoblasts to elevated glucose, NEFA or the combination of both induced cytokine production by these cells, trophoblasts were cultured for $24 \mathrm{~h}$ in RPMI complete medium containing $0.5 \% \mathrm{BSA}$ at 1 or $10 \mathrm{mM}$ glucose in the presence or absence of $0.25 \mathrm{mM}$ NEFA (palmitate:oleate ratio, $1: 1$ ). Production of TNF $\alpha$, IL-1 $\beta$, IL- 6 and IL-10 was detected in the culture medium after $6 \mathrm{~h}$ incubation and concentrations were higher at $24 \mathrm{~h}$. Secretion of these cytokines was increased by the presence of NEFA, but was unaffected by the glucose concentration
(Fig. 5A-D). Trophoblasts secreted large amounts of IL-8. Secretion of IL-8, however, was not affected by the level of glucose or the presence of NEFA (data not shown).

\section{Discussion}

Elevated glucose and lipids have been implicated in the pathogenesis of fetal/neonatal complications of diabetic pregnancy. Whether their effects are independent of each other, or whether they act synergistically via a process termed "glucolipotoxicity" [29] is unknown. Our studies of primary human trophoblast cells in culture showed that a palmitate and oleate NEFA mix had marked 


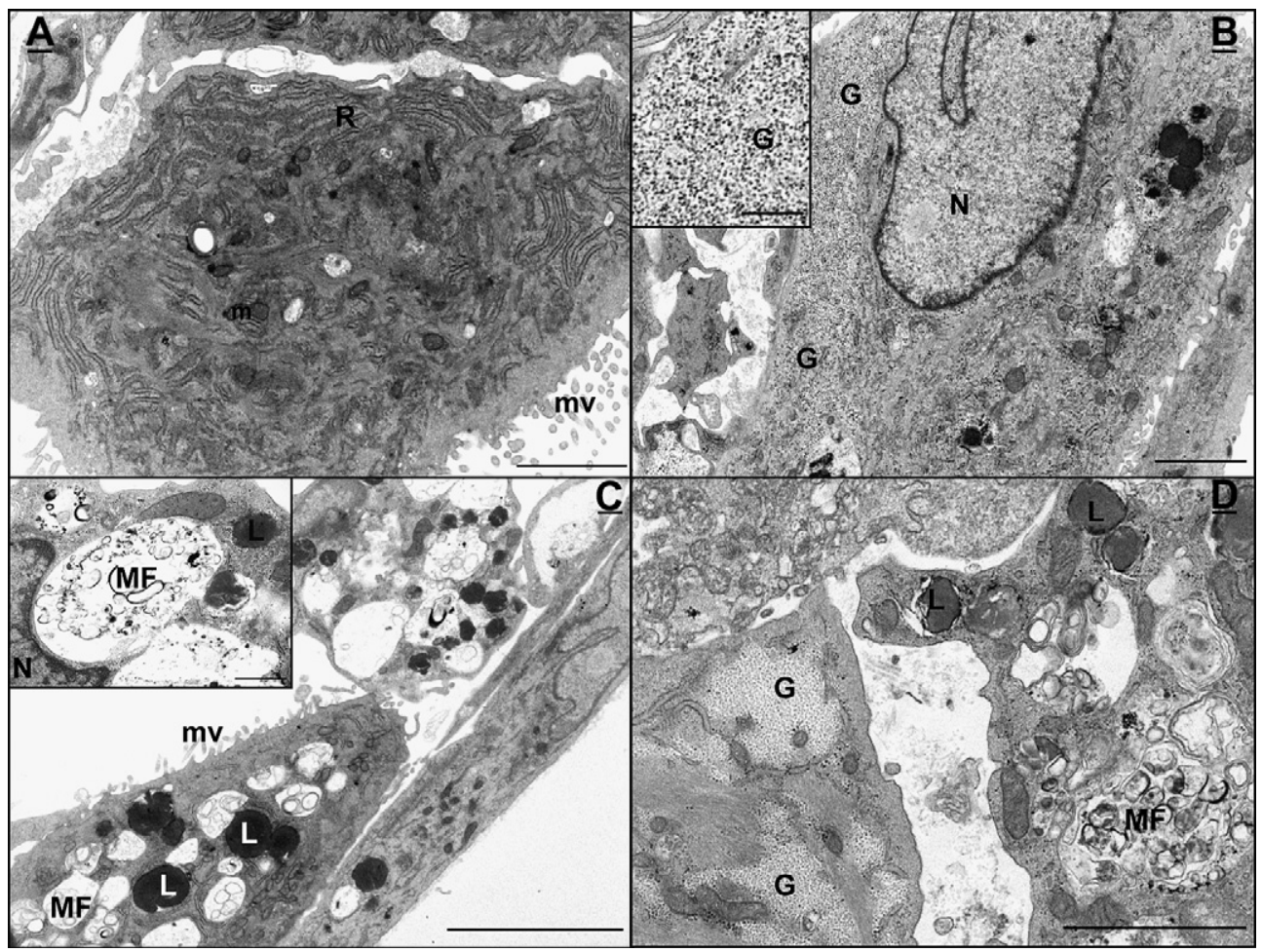

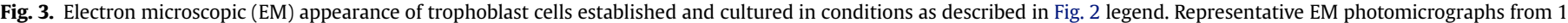

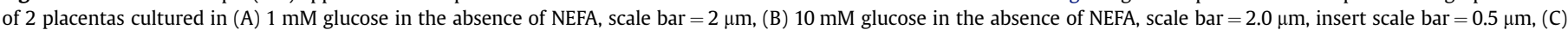

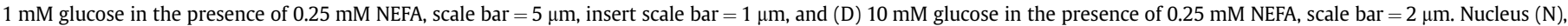
rough endoplasmic reticulum $(R)$, mitochondria $(m)$, glycogen lakes $(G)$, lipid droplets $(\mathrm{L})$ and myelin figures (MF).

effects on trophoblast cell morphology and behavior independent of the glucose concentration. NEFA were avidly incorporated into lipid droplets, caused trophoblast cells to fuse to form syncytia, and promoted pro-inflammatory cytokine secretion. There was little evidence for interaction of glucose and NEFA on the measured parameters except for lipid droplet formation. A glucose concentration of $10 \mathrm{mM}$ compared to $1 \mathrm{mM}$ attenuated the marked effect of NEFA to increase the expression of the lipid droplet-associated protein adipophilin and to form lipid droplets. Thus, dyslipidaemia may have a significant pathogenic role in the placentas of pregnant women with diabetes and obesity, with the majority of the effects independent of the glucose concentration. The effect of glucose to alter lipid droplet formation, however, could turn out to be a very important glucose/lipid interaction, as the elevated glucose may be inhibiting a mechanism by which trophoblasts buffer an elevated NEFA supply.

\subsection{Glucose metabolism in human trophoblasts}

We found glucose utilisation via glycolysis in the trophoblasts had a very low glucose substrate $\mathrm{K}_{\mathrm{m}}$ of $0.6 \mathrm{mM}$ and was almost maximal at the low physiological glucose concentration of $4 \mathrm{mM}$. This result is consistent with previous studies of perfused human placental cotyledons that showed no increase in lactate production for increases in the perfusate glucose concentration from $4.0 \mathrm{mM}$ [19] and no increases in $\mathrm{O}_{2}$ consumption from $5.5 \mathrm{mM}$ [36]. Total glucose utilisation in both these perfused placenta studies, however, continued to increase with maternal glucose perfusate concentrations well above these levels $[19,36]$. This non-oxidative glucose utilisation may be into glycogen storage and/or into the pentose-phosphate pathway as previously suggested [36] (Fig. 6A). Hence, glycolysis in trophoblasts is likely to be running at near maximum when maternal blood glucose is physiological and it will not be increased by hyperglycaemia. It follows that flux into glucose metabolic pathways below glycolysis, such as glucose oxidation via the tricarboxylic acid cycle, anaplerosis and lipogenesis, will also not increase with diabetic hyperglycaemia (Fig. 6A). The accumulation of glycogen on EM examination of trophoblasts cultured in $10 \mathrm{mM}$ compared to $1 \mathrm{mM}$ glucose, however, is consistent with glycogen synthesis being increased by hyperglycaemia.

\subsection{Fatty acid oxidation in human trophoblasts}

It has been generally believed that fatty acid oxidation is a minor contributor to placental energy supply [21], although this has recently been challenged $[37,38]$. In the current study, fatty acid oxidation in trophoblast cells was measured at a rate of about $0.6 \mathrm{nmol} / 10^{6}$ cells $/ \mathrm{h}$ which is consistent with results from a previous study [37]. At a concentration of $0.1 \mathrm{mM}$ palmitate, fatty acid esterification into TG, DAG and PL combined was only about $0.25 \mathrm{nmol} / 10^{6}$ cells $/ \mathrm{h}$, which is at variance with previous reports stating that fatty acid esterification is much more active than oxidation in placenta [21]. Considering that complete oxidation of palmitate can yield 129 ATP molecules and glucose metabolism to lactate, which is the predominant pathway of its metabolism in placenta, only produces two ATP, fatty acids may well make a significant contribution to placental energy needs. Use of fatty acids for placental energy requirements may preserve the available glucose supply for fetal requirements, particularly during fasting.

It is well established that an increase in glucose supply inhibits fatty acid oxidation and promotes fatty acid esterification in some tissues [30,39]. Metabolism of glucose can elevate malonyl-CoA, a signal of plenty, which is an allosteric inhibitor of 

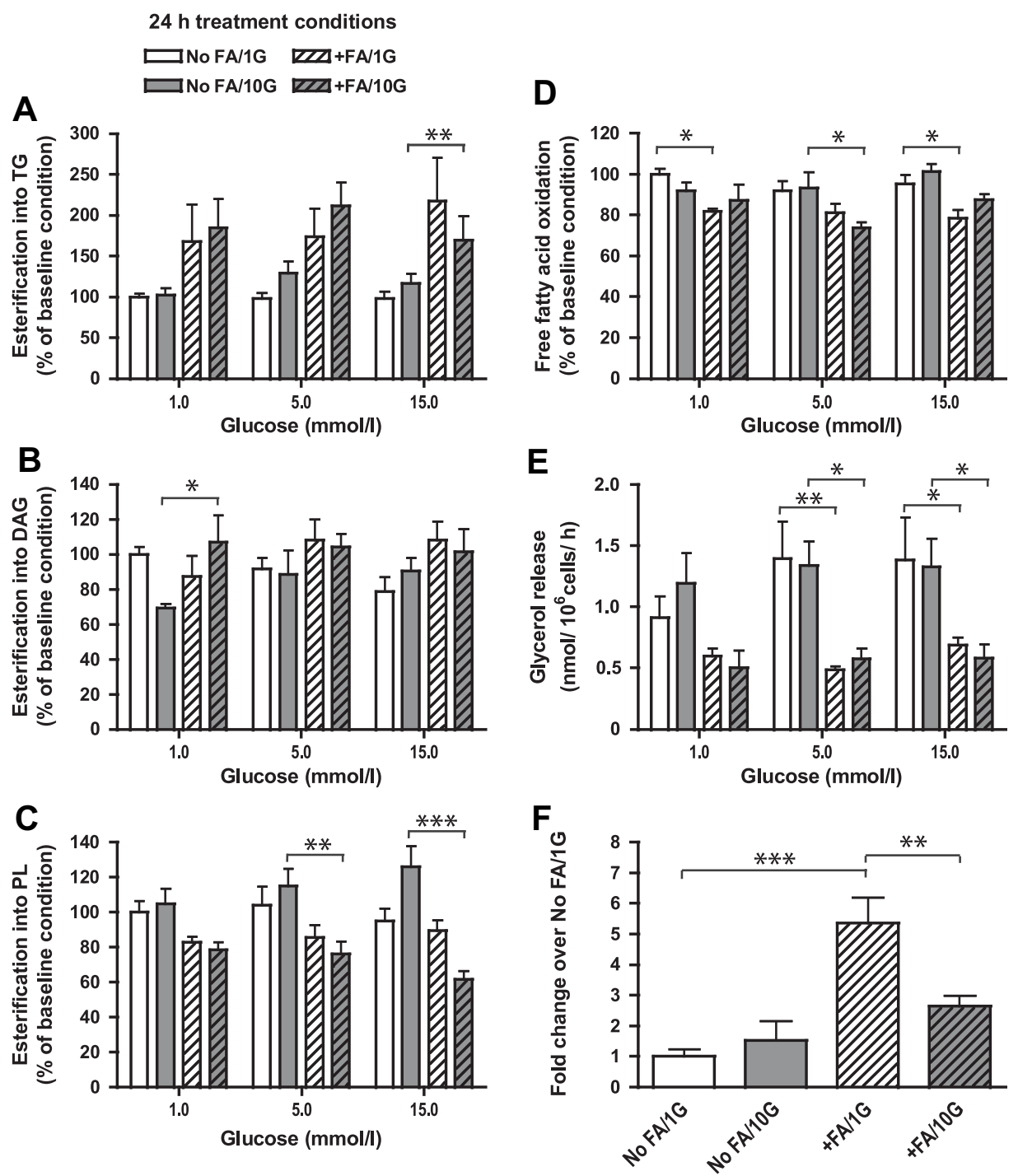

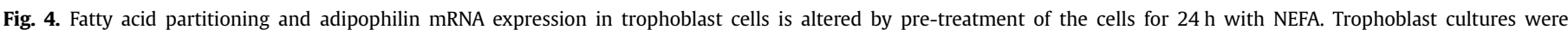

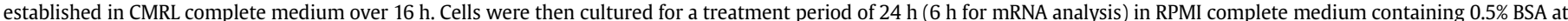

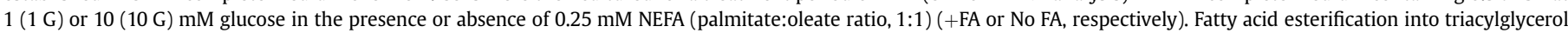

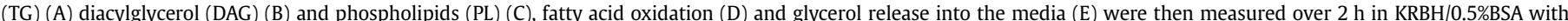

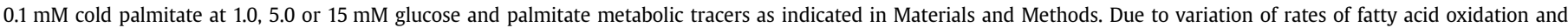

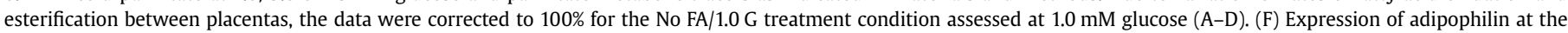

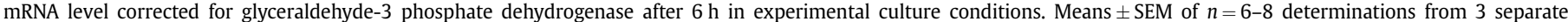

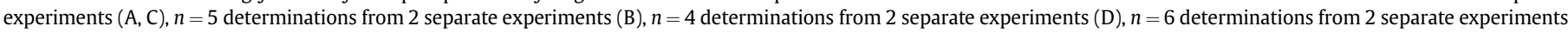

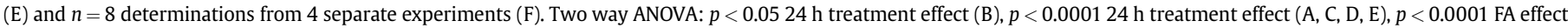
(F), $p<0.01 \mathrm{FA}$ and glucose interaction (F). Bonferroni post hoc test: ${ }^{*} p<0.05,{ }^{* *} p<0.01$ and ${ }^{* * *} p<0.001$.

carnitine palmitoyltransferase 1 , a rate limiting enzyme for mitochondrial fatty acid oxidation [30,39]. In the current study of trophoblasts, glucose had no effect on the rate of fatty acid oxidation, whether across the range of glucose concentrations that affect glycolysis rate $(0.5-5.0 \mathrm{mM})$ or across a higher range $(2.0-18 \mathrm{mM})$. It is possible that this is due to low levels of acetylCoA carboxylase in placenta [21], the enzyme involved in the generation of malonyl-CoA. (Fig. 6A and B).

\subsection{Fatty acid esterification in human trophoblasts}

Fatty acid esterification in trophoblasts was measured at physiological (0.1 mM, FA:BSA ratio 1.3), high physiological (0.2 mM, FA:BSA ratio 2.7$)$ and supra-physiological $(0.4 \mathrm{mM}$, FA:BSA ratio 5.4 (saturation occurs with ratio of 7)) NEFA concentrations. With the more physiological NEFA concentrations, glucose either from 0.5 to $5.0 \mathrm{mM}$ over 2 h or from 5.5 to $15.0 \mathrm{mM}$ over 24 h had no effect on fatty acid esterification rates. Glucose did seem to increase fatty acid esterification at the highest NEFA concentration, particularly over $24 \mathrm{~h}$, but this may have little physiological relevance. Most striking in these experiments was the finding that there was no evidence of a plateau in fatty acid esterification rates into DAG and TG, even over $24 \mathrm{~h}$, with increases in the NEFA concentration to very high levels. There was, however, some suggestion of attenuation of esterification into PL.

\subsection{NEFA induced lipid droplet formation in trophoblasts is attenuated by high glucose}

Culture in the presence of fatty acids caused the appearance of lipid droplets within $6 \mathrm{~h}$ using oil red-O staining with confirmation 

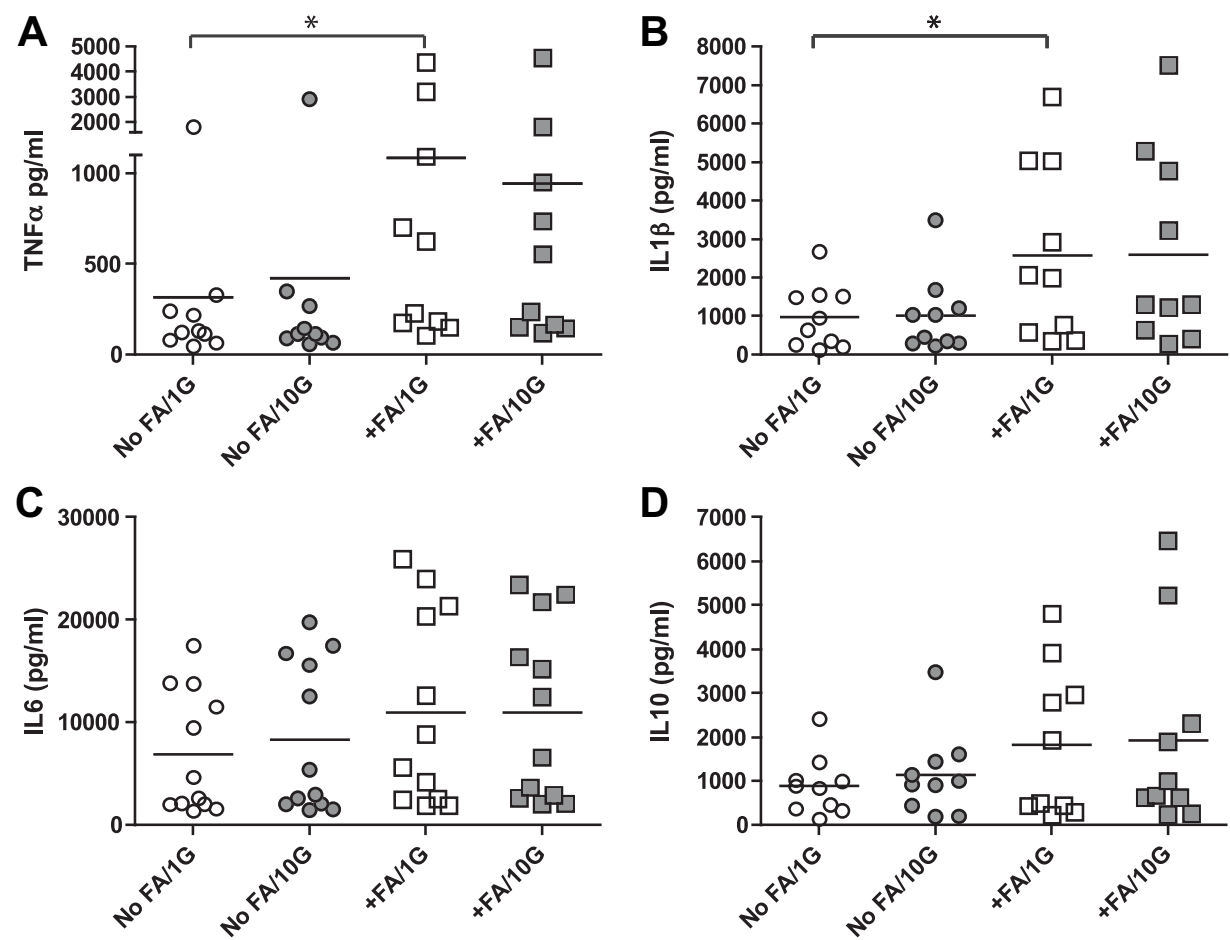

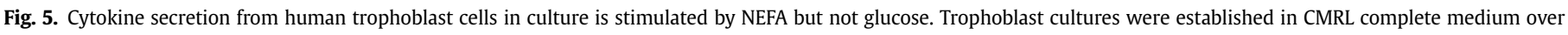

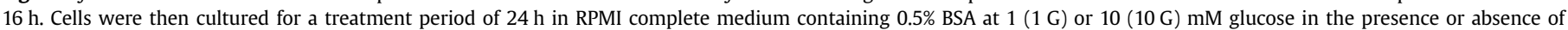

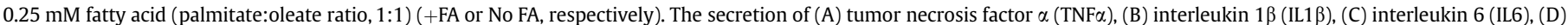

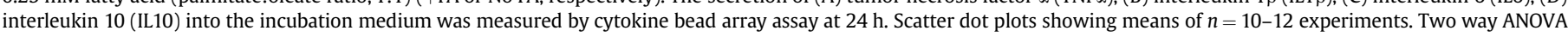
with placenta matching: $p<0.05$ FA effect (C, D), $p<0.01$ FA effect (A, B). Bonferroni post hoc test: ${ }^{*} p<0.05$.

by EM (Fig. 6B). This finding is consistent with a previous study in human trophoblasts in which a mix of oleic and linoleic acid, particularly in the presence of insulin in serum free medium, also induced the formation of lipid droplets in addition to enhancing the expression of adipophilin [40]. Considerable evidence now exists pointing to a role for peroxisomal proliferator-activated receptor $\gamma$ (PPAR $\gamma$ ) and adipophilin expression in the promotion of lipid droplet formation and lipid metabolism in the trophoblast [41-44], implicating this transcription factor in this effect of NEFA. Our EM lipid droplet accumulation and adipophilin mRNA expression results indicate that elevated glucose attenuates this effect (Fig. 6B). Of note, similar results in primary human trophoblasts with respect to glucose/NEFA interactions and lipid droplet formation have recently been reported by another group [28]. The significance of the plentiful myelin figures seen on EM of cells cultured in the presence of NEFA is unknown but may be a response to cell injury. Lipid droplets, myelin figures and glycogen deposits have been observed in trophoblasts of placentas from 20 day heat-stressed rats [45].

\subsection{NEFA alter their own partitioning to enhance placental fatty acid buffering}

Culture of trophoblasts in the presence of NEFA for $24 \mathrm{~h}$ altered the subsequent intracellular partitioning of fatty acids. Fatty acid esterification into TG was substantially enhanced, esterification into PL was attenuated and there was a dramatic reduction in glycerol release, suggesting a reduction in intracellular lipolysis (Fig. 6B). These changes would be consistent with an effect of the fatty acids to upregulate their own partitioning into TG. As with the capacity of the placenta to buffer the fetus from excess glucose through storing it safely in the form of glycogen, these changes in lipid partitioning would favour the safe storage of excess lipid supply within lipid droplets [46]. Fatty acids have previously been found to reduce placental lipoprotein lipase, an extracellular lipase that is involved in hydrolyzing TG from maternal circulating lipoproteins to allow uptake of the lipoprotein fatty acids into the cell [47], potentially another mechanism to protect the fetus from excess lipid (Fig. 6B).

With respect to intracellular lipolysis, the effects of fatty acids in trophoblasts to reduce glycerol release is at complete variance with the effect of oleate in a breast cancer cell line [48]. While the reduced glycerol release in trophoblasts in the presence of fatty acids could be due to reduced lipolysis, another potential explanation is upregulation of glycerol kinase activity. Little is known about the presence or activity of this enzyme in placenta. The regulation of lipolysis and importance of intracellular glycerolipid/ fatty acid cycling within trophoblasts warrants attention. Also, the possibility that the trophoblast synthesizes and exports lipoprotein-like particles, for which there is a small amount of evidence [49], should be further investigated (Fig. 6B).

\subsection{NEFA induce trophoblast syncytialisation and pro-inflammatory cytokine production}

The exposure of the trophoblasts over $24 \mathrm{~h}$ to NEFA had a marked effect on promoting trophoblast aggregation and syncytialisation. This novel finding, however, was not associated with any alteration in the parameters of cell viability or growth. Also, within the time frame of these experiments, syncytialisation was not coupled with increases in the production of $\beta$-HCG, placental lactogen or progesterone. This is not consistent with the current wisdom amongst placentologists. Another group, however, has recently found that $\beta$-HCG secretion is not necessarily linked to cell 

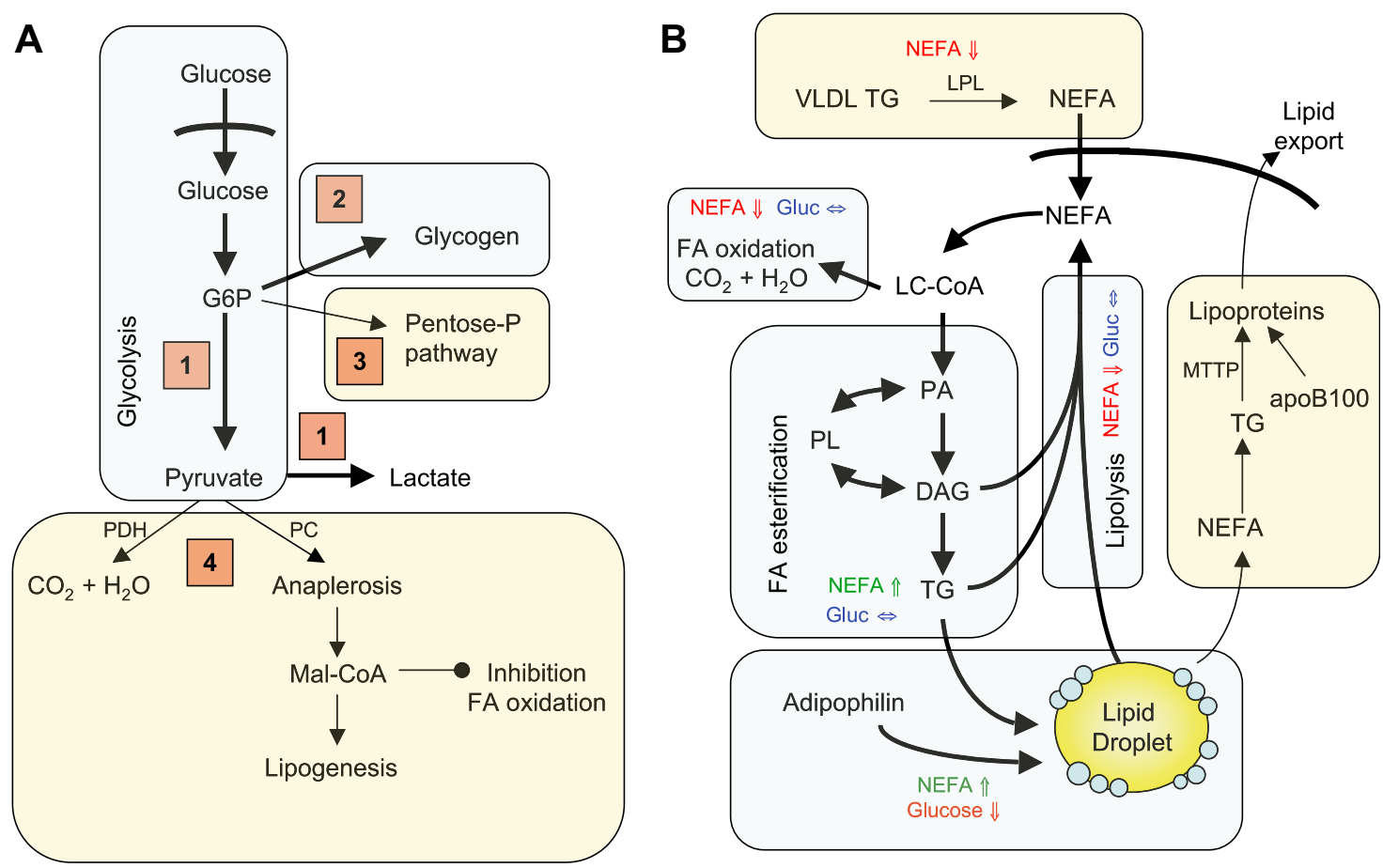

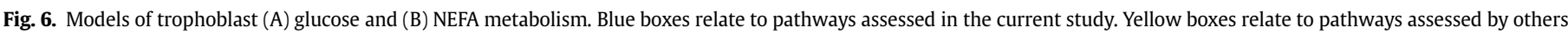

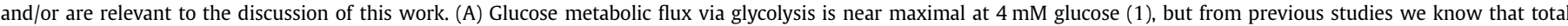

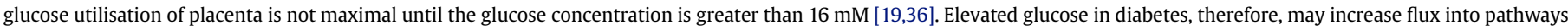

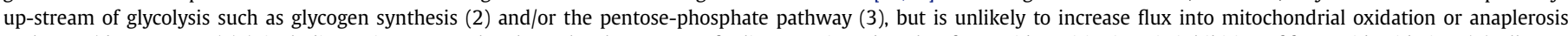

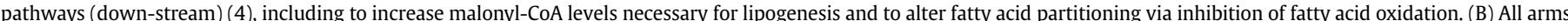

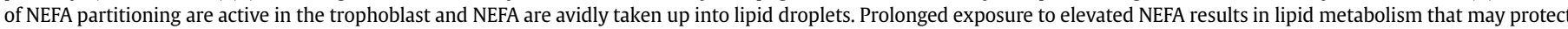

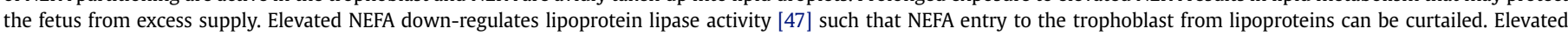

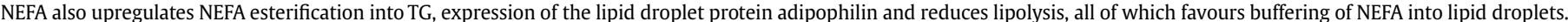

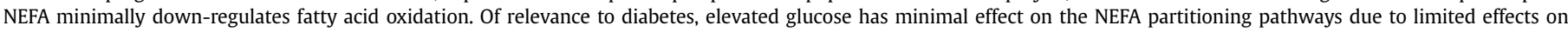

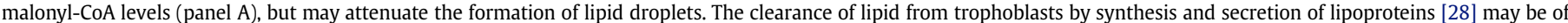

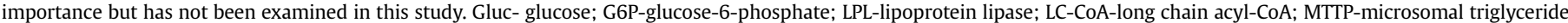
transfer protein; PA-phosphatidic acid; VLDL-very low density lipoprotein.

fusion in BeWo cells (personal communication, Kristina Orendi, Medical University of Graz). Of considerable interest was the finding that the NEFA mix stimulated trophoblast cytokine production, with no effect of the higher glucose concentration. Thus, maternal dyslipidaemia could have roles in promoting placental structural abnormalities and pro-inflammatory change as have been observed in placentas of gestational diabetic [50] and obese women [23].

\subsection{Conclusion}

The results of this work underscore the potential importance of dyslipidaemia in the pathophysiology of placental dysfunction and fetal abnormalities in diabetic pregnancy. The finding that NEFA enhance their own storage into lipid droplets is indicative of upregulation of a buffering mechanism to protect the fetus from excess lipid. The novel findings that NEFA promote syncytialisation and cytokine production may be indicative of harmful effects of dyslipidaemia via effects on placental structure and inflammation. It was remarkable how little effect glucose had on trophoblasts compared to the effects of NEFA. Glucose did not alter fatty acid partitioning as was predicted by the glucolipotoxicity hypothesis. Dyslipidaemia, therefore, may have greater pathogenic significance than hyperglycaemia at the level of this cell in diabetic pregnancy. Elevated glucose, however, did impede NEFA-induced lipid droplet formation, the importance of which warrants further examination.

\section{Acknowledgements}

This work was supported by grants from the Canberra Region Medical Research Foundation, The Canberra Hospital Private Practice Fund and a National Health and Medical Research Council Project Grant (418077). We wish to thank Drs Sylvie Hauguel-de Mouzon, Marc Prentki and Alison Kent for critically reviewing the manuscript.

\section{Appendix. Supplementary material}

Supplementary data associated with this article can be found in the online version, at doi:10.1016/j.placenta.2009.12.013.

\section{References}

[1] Callaway LK, Prins JB, Chang AM, McIntyre HD. The prevalence and impact of overweight and obesity in an Australian obstetric population. Med J Aust 2006;184:56-9.

[2] Metzger BE, Lowe LP, Dyer AR, Trimble ER, Chaovarindr U, Coustan DR, et al Hyperglycemia and adverse pregnancy outcomes. N Engl J Med 2008;358:1991-2002.

[3] McElduff A, Ross GP, Lagstrom JA, Champion B, Flack JR, Lau SM, et al. Pregestational diabetes and pregnancy: an Australian experience. Diabetes Care 2005;28:1260-1.

[4] Cundy T, Gamble G, Townend K, Henley PG, MacPherson P, Roberts AB. Perinatal mortality in Type 2 diabetes mellitus. Diabet Med 2000;17:33-9.

[5] Clausen TD, Mathiesen E, Ekbom P, Hellmuth E, Mandrup-Poulsen T, Damm P. Poor pregnancy outcome in women with type 2 diabetes. Diabetes Care 2005;28:323-8. 
[6] Herrera E. Metabolic adaptations in pregnancy and their implications for the availability of substrates to the fetus. Eur J Clin Nutr 2000;54(Suppl. 1):S47-51.

[7] Nolan CJ, Riley SF, Sheedy MT, Walstab JE, Beischer NA. Maternal serum triglyceride, glucose tolerance, and neonatal birth weight ratio in pregnancy. Diabetes Care 1995;18:1550-6.

[8] Potter JM, Nestel PJ. The hyperlipidemia of pregnancy in normal and complicated pregnancies. Am J Obstet Gynecol 1979;133:165-70.

[9] Koukkou E, Watts GF, Lowy C. Serum lipid, lipoprotein and apolipoprotein changes in gestational diabetes mellitus: a cross-sectional and prospective study. J Clin Pathol 1996;49:634-7.

[10] Hollingsworth DR, Grundy SM. Pregnancy-associated hypertriglyceridemia in normal and diabetic women. Differences in insulin-dependent, non-insulindependent, and gestational diabetes. Diabetes 1982;31:1092-7.

[11] Ramsay JE, Ferrell WR, Crawford L, Wallace AM, Greer IA, Sattar N. Materna obesity is associated with dysregulation of metabolic, vascular, and inflammatory pathways. J Clin Endocrinol Metab 2002;87:4231-7.

[12] Chen X, Scholl TO. Association of elevated free fatty acids during late pregnancy with preterm delivery. Obstet Gynecol 2008;112:297-303.

[13] Alvino G, Cozzi V, Radaelli T, Ortega H, Herrera E, Cetin I. Maternal and feta fatty acid profile in normal and intrauterine growth restriction pregnancies with and without preeclampsia. Pediatr Res 2008;64:615-20.

[14] Schaefer-Graf UM, Graf K, Kulbacka I, Kjos SL, Dudenhausen J, Vetter K, et al Maternal lipids as strong determinants of fetal environment and growth in pregnancies with gestational diabetes mellitus. Diabetes Care 2008; 31:1858-63.

[15] Calderon IM, Damasceno DC, Amorin RL, Costa RA, Brasil MA, Rudge MV. Morphometric study of placental villi and vessels in women with mild hyperglycemia or gestational or overt diabetes. Diabetes Res Clin Pract 2007;78:65-71.

16] Evers IM, Nikkels PG, Sikkema JM, Visser GH. Placental pathology in women with type 1 diabetes and in a control group with normal and large-forgestational-age infants. Placenta 2003;24:819-25.

[17] Schafer-Graf UM, Dupak J, Vogel M, Dudenhausen JW, Kjos SL, Buchanan TA et al. Hyperinsulinism, neonatal obesity and placental immaturity in infants born to women with one abnormal glucose tolerance test value. J Perinat Med 1998;26:27-36.

[18] Honda M, Toyoda C, Nakabayashi M, Omori Y, Quantitative investigations of placental terminal villi in maternal diabetes mellitus by scanning and transmission electron microscopy. Tohoku J Exp Med 1992;167:247-57.

[19] Osmond DT, Nolan CJ, King RG, Brennecke SP, Gude NM. Effects of gestational diabetes on human placental glucose uptake, transfer, and utilisation. Diabetologia 2000;43:576-82.

[20] Hauguel-de Mouzon S, Shafrir E. Carbohydrate and fat metabolism and related hormonal regulation in normal and diabetic placenta. Placenta 2001:22:619-27.

[21] Desoye G, Shafrir E. Placental metabolism and its regulation in health and diabetes. Mol Aspects Med 1994;15:505-682.

[22] Hahn T, Barth S, Weiss U, Mosgoeller W, Desoye G. Sustained hyperglycemia in vitro down-regulates the GLUT1 glucose transport system of cultured human term placental trophoblast: a mechanism to protect fetal development? FASEB J 1998;12:1221-31.

[23] Challier JC, Basu S, Bintein T, Minium J, Hotmire K, Catalano PM, et al. Obesity in pregnancy stimulates macrophage accumulation and inflammation in the placenta. Placenta 2008;29:274-81.

[24] Szabo AJ, Szabo O. Placental free-fatty-acid transfer and fetal adipose-tissue development: an explantation of fetal adiposity in infants of diabetic mothers. Lancet 1974;2:498-9.

[25] Kaminsky S, Sibley CP, Maresh M, Thomas CR, D'Souza SW. The effects of diabetes on placental lipase activity in the rat and human. Pediatr Res 1991:30:541-3.

[26] Magnusson AL, Waterman IJ, Wennergren M, Jansson T, Powell TL. Triglyceride hydrolase activities and expression of fatty acid binding proteins in the human placenta in pregnancies complicated by intrauterine growth restriction and diabetes. J Clin Endocrinol Metab 2004;89:4607-14.

[27] Lindegaard ML, Damm P, Mathiesen ER, Nielsen LB. Placental triglyceride accumulation in maternal type 1 diabetes is associated with increased lipase gene expression. J Lipid Res 2006;47:2581-8.

[28] Radaelli T, Lepercq J, Varastehpour A, Basu S, Catalano PM, Hauguel-De Mouzon S. Differential regulation of genes for fetoplacental lipid pathways in pregnancy with gestational and type 1 diabetes mellitus. Am J Obstet Gynecol 2009;201:209. e201-209 e210.

[29] Prentki M, Corkey BE. Are the beta-cell signaling molecules malonyl-CoA and cystolic long-chain acyl-CoA implicated in multiple tissue defects of obesity and NIDDM? Diabetes 1996:45:273-83.
[30] Roduit R, Nolan C, Alarcon C, Moore P, Barbeau A, Delghingaro-Augusto V, et al. A role for the malonyl-CoA/long-chain acyl-CoA pathway of lipid signaling in the regulation of insulin secretion in response to both fuel and nonfuel stimuli. Diabetes 2004;53:1007-19.

[31] El-Assaad W, Buteau J, Peyot ML, Nolan C, Roduit R, Hardy S, et al. Saturated fatty acids synergize with elevated glucose to cause pancreatic beta-cell death. Endocrinology 2003;144:4154-63.

[32] Kliman HJ, Nestler JE, Sermasi E, Sanger JM, Strauss 3rd JF. Purification, characterization, and in vitro differentiation of cytotrophoblasts from human term placentae. Endocrinology 1986;118:1567-82.

[33] Kangani CO, Kelley DE, Delany JP. New method for GC/FID and GC-C-IRMS analysis of plasma free fatty acid concentration and isotopic enrichment. J Chromatogr B Analyt Technol Biomed Life Sci 2008;873:95-101.

[34] Segall L, Lameloise N, Assimacopoulos-Jeannet F, Roche E, Corkey P, Thumelin S, et al. Lipid rather than glucose metabolism is implicated in altered insulin secretion caused by oleate in INS-1 cells. Am J Physiol 1999;277:E521-8.

[35] Peyot ML, Nolan CJ, Soni K, Joly E, Lussier R, Corkey BE, et al. Hormonesensitive lipase has a role in lipid signaling for insulin secretion but is nonessential for the incretin action of glucagon-like peptide 1. Diabetes 2004;53:1733-42.

[36] Hauguel S, Desmaizieres V, Challier JC. Glucose uptake, utilization, and transfer by the human placenta as functions of maternal glucose concentration. Pediatr Res 1986;20:269-73.

[37] Shekhawat P, Bennett MJ, Sadovsky Y, Nelson DM, Rakheja D, Strauss AW. Human placenta metabolizes fatty acids: implications for fetal fatty acid oxidation disorders and maternal liver diseases. Am J Physiol Endocrinol Metab 2003;284:E1098-105.

[38] Oey NA, den Boer ME, Ruiter JP, Wanders RJ, Duran M, Waterham HR, et al. High activity of fatty acid oxidation enzymes in human placenta: implications for fetal-maternal disease. J Inherit Metab Dis 2003;26:385-92.

[39] McGarry JD, Brown NF. The mitochondrial carnitine palmitoyltransferase system. From concept to molecular analysis. Eur J Biochem 1997;244:1-14.

[40] Elchalal U, Schaiff WT, Smith SD, Rimon E, Bildirici I, Nelson DM, et al. Insulin and fatty acids regulate the expression of the fat droplet-associated protein adipophilin in primary human trophoblasts. Am J Obstet Gynecol 2005;193:1716-23.

[41] Schaiff WT, Knapp Jr FF, Barak Y, Biron-Shental T, Nelson DM, Sadovsky Y. Ligand-activated peroxisome proliferator activated receptor gamma alters placental morphology and placental fatty acid uptake in mice. Endocrinology 2007; 148:3625-34.

[42] Schaiff WT, Bildirici I, Cheong M, Chern PL, Nelson DM, Sadovsky Y. Peroxisome proliferator-activated receptor-gamma and retinoid $\mathrm{X}$ receptor signaling regulate fatty acid uptake by primary human placental trophoblasts. J Clin Endocrinol Metab 2005;90:4267-75.

[43] Bildirici I, Roh CR, Schaiff WT, Lewkowski BM, Nelson DM, Sadovsky Y. The lipid droplet-associated protein adipophilin is expressed in human trophoblasts and is regulated by peroxisomal proliferator-activated receptor-gamma/ retinoid X receptor. J Clin Endocrinol Metab 2003;88:6056-62.

[44] Capobianco E, White V, Higa R, Martinez N, Jawerbaum A. Effects of natural ligands of PPARgamma on lipid metabolism in placental tissues from healthy and diabetic rats. Mol Hum Reprod 2008;14:491-9.

[45] Padmanabhan R, Al-Menhali NM, Ahmed I, Kataya HH, Ayoub MA. Histological, histochemical and electron microscopic changes of the placenta induced by maternal exposure to hyperthermia in the rat. Int J Hyperthermia 2005;21:29-44.

[46] Nolan CJ, Larter CZ. Lipotoxicity: why do saturated fatty acids cause and monounsaturates protect against it? J Gastroenterol Hepatol 2009;24:703-6.

[47] Magnusson-Olsson AL, Lager S, Jacobsson B, Jansson T, Powell TL. Effect of maternal triglycerides and free fatty acids on placental LPL in cultured primary trophoblast cells and in a case of maternal LPL deficiency. Am J Physiol Endocrinol Metab 2007;293:E24-30.

[48] Przybytkowski E, Joly E, Nolan CJ, Hardy S, Francoeur AM, Langelier Y, et al. Upregulation of cellular triacylglycerol - free fatty acid cycling by oleate is associated with long-term serum-free survival of human breast cancer cells. Biochem Cell Biol 2007;85:301-10.

[49] Madsen EM, Lindegaard ML, Andersen CB, Damm P, Nielsen LB. Human placenta secretes apolipoprotein B-100-containing lipoproteins. J Biol Chem 2004:279:55271-6.

[50] Radaelli T, Varastehpour A, Catalano P, Hauguel-de Mouzon S. Gestational diabetes induces placental genes for chronic stress and inflammatory pathways. Diabetes 2003;52:2951-8. 